\title{
Por uma voz que seja dança: Reflexões sobre a oralidade no balé a partir do solo Veronique Doisneau (2004)
}

\author{
For a voice to be dance: Reflections about \\ orality into the ballet through Veronique \\ Doisneau solo (2004)
}

Rousejanny da Silva FERREIRA ${ }^{1}$

Michael SILVA ${ }^{2}$

\section{Resumo}

Este artigo aborda a utilização e recusa da oralidade na cena do balé e como isto foi posto a prova em uma dança: Veronique Doisneau [Paris, 2004]. Esta obra desvela o não visto em cena das companhias de balé clássico e o prolongamento disso na vida da bailarina Veronique. Sendo este um trabalho conduzido pela fala, levantamos algumas questões sobre os sentidos da voz como corpo, performance e dança.

Palavras-chave: Dança; Balé; Performance; Oralidade.

\section{Abstract}

This article discusses the use and refusal of orality in the ballet scene and how it was put to the test in a dance: Veronique Doisneau [Paris, 2004]. This dance work reveals the unseen in the scenes of the classical ballet companies and the projection of this in Veronique's life. Considering this work is conducted by speech, we thought some questions about the voice as body, performance and dance.

Keywords: Dance; Ballet; Performance; Orality.

1. Graduada em Ed. Física/ UEG; especialista em Filosofia da Arte/IFITEG-UEG e Pedagogias da Dança/ PUC-GO e mestre em Performances Culturais/ UFG. Coordenou e lecionou no curso de Licenciatura em Dança/IFB. Docente do curso de Licenciatura em Dança/ IFG. Bailarina e pesquisadora de ensino e história da dança acadêmica com ênfase no balé. E-mail: rousedance. ferreira@gmail.com

2. Graduado em Letras, Línguas Portuguesa e Ing. e suas Literaturas/UFT; foi bailarino nas companhias de dança de Araguaína, Colinas/ TO e Quasar Jovem/GO; mestrando em Performances Culturais/UFG; pesquisador de dança contemporânea, performance e literatura. E-mail: mic.dancer@hotmail.com 
Ópera Nacional de Paris [França] - Palácio Garnier, setembro de 2004. Teatro lotado a espera da estreia do solo Veronique Doisneau. Veronique é bailarina da casa e, para este trabalho, teve a direção do coreógrafo Jerôme Bel ${ }^{3}$ [1964, França]. Abrem-se as cortinas: não há cenário, música ou iluminação elaborada. Entra no palco Veronique com roupa de ensaio, carregando em seus braços uma saia de balé romântico ${ }^{4}$, um par de sapatilhas e uma garrafa d'água. Ela lentamente olha para a plateia e começa:

Boa noite.

Meu nome é Veronique Doisneau.

Eu sou casada e tenho dois filhos, um de seis e outro de doze anos.

Eu tenho quarenta e dois anos e aposento-me em oito dias.

Hoje a noite é minha ultima apresentação pela Ópera de Paris.

Para aqueles que estão distantes, as pessoas dizem que eu me pareço com a atriz francesa Isabelle Huppert.

Quando tinha vinte anos, eu fiz uma cirurgia de hérnia de disco pra reparar alguns danos.

Pois eu corria o risco de nunca mais voltar a dançar.

Na hierarquia da Ópera Ballet de Paris eu sou um sujet [sujeito].

Isso significa que eu posso dançar tanto no Corpo de Baile quanto alguns papéis de solista.

Eu ganho cerca de três mil e seiscentos euros por mês, aproximadamente vinte e três mil francos franceses.

Eu nunca fui uma estrela.

Isso nunca foi cogitado. Eu acho que eu não tinha talento o bastante e também era frágil fisicamente.

[Pausa de respiração de quatro segundos]

O encontro com Rudolf Nureyev ${ }^{5}$

foi fundamental para mim.

Ele entendia de tudo

e nos deu uma ideia:

É através do domínio da linguagem da dança

que a emoção é criada.

Acima de tudo, ele nos disse para
4. Saia de tule de $3 / 4$ de com $\neg$ pri $\neg$ mento, geralmente branca, que cai entre $o$ joe-lho e o tornozelo.
5. Célebre bailarino russo [1938-1993] do Kirov Ballet refugiado na França em 1961 País onde tornou-se diretor do Ballet da Ópera de Paris em 1983. 
respeitar o sentido do movimento.

E que não tentássemos interpretá-lo.

À propósito, eu adoro dançar a

segunda variação

de The shades pas de trois

do terceiro ato de La Bayadère ${ }^{6}$

[a bailarina deposita seu tutu e a

garrafa d’água no chão, anda até a

diagonal ao fundo esquerdo do palco

e realiza a variação mencionada

deslocando-se pelo espaço do palco

e cantarola a música de tal balé].

(DOISNEAU, 2004)

E assim, segue a apresentação da bailarina: entre relatos do cotidiano de uma companhia de balé e demonstrações de trechos coreográficos que marcaram sua carreira. Voz que, além de narrar o trabalho, cumpre também o importante papel de marcar os ritmos sonoros das músicas que embalariam sua dança, caso tocadas. Importa saber que iniciamos este texto com a descrição da cena inicial da obra Veronique Doisneau para tratarmos de uma questão pouco recorrente no balé: a voz como performance ${ }^{7}$ em cena. Uma vez que, tida comumente como uma expressão do corpo pelo movimento, as construções do balé pouco exploraram a potência da voz, da palavra e/ou das significações verbais como recurso corporal passível de ser usado para a elaboração de uma obra de dança. Como veremos abaixo e no decorrer do trabalho.

De acordo com o estudioso de dança André Lepecki [1965, Brasil-EUA], em palestra no projeto Nada Expandido em Brasília, no ano de 2012, a definição de dança como expressão do movimento surgiu como paradigma da modernidade, que consolidou a dança como a arte de manter-se constantemente em movimento. Consequentemente a esse pensamento, a voz e seus efeitos, assim como o uso de outros possíveis elementos para a cena, não foram investimentos massivamente difundidos no período inicial da modernidade da dança cênica. Significa dizer que só depois de desestabilizada essa máxima é que a relação entre o verbal e o não-verbal, nesta arte, foi amplamente explorada; especialmente pela iniciativa de alguns movimentos contemporâneos que enfatizaram questões políticas e conceituais da dança e do corpo.

Para trazer um exemplo reiterado do pensamento moderno da dança em relação ao corpo e a voz, recorremos a Rudolf Von Laban [1879-1958, Eslováquia], importante pensador deste campo artístico na primeira metade do século XX. De acordo com ele:
6. Balé em três atos estreado em 1877 no Teatro Mariinsky [São Petersburgo/Rússia]. Coreografias de Marius Petipa [1818-1910], música de Ludwig Minkus [1826-1917] e libreto de Marius Petipa e Sergey Khudyakov [s.d.].
7. Quando falamos aqui em performance, a compreendemos tal como Paul Zumthor (2000). Autor para o qual ela é um ato de comunicação poética que marca e abre caminhos para a recepção coletiva formada através de elementos visuais, auditivos e/ou táteis lançados à percepção sensorial. 
A dança como composição de movimento pode ser comparada à linguagem oral. Assim como as palavras são formadas por letras, os movimentos são formados por elementos; assim como as orações são compostas de palavras, as frases da dança são compostas de movimento. Esta linguagem de movimento, de acordo com seu conteúdo, estimula a atividade mental de maneira semelhante, e talvez até mais complexa que a da palavra falada. (LABAN, 1990, p.31)

Como vimos acima, o protagonismo do movimento na dança é reafirmado nesta passagem textual como uma espécie de morfossintaxe complexa do corpo. Ao tecer suas considerações sobre a presença do verbal no palco coreográfico, por seu turno, a estudiosa Laurence Louppe [1938-2012, França] atesta ter havido pelo menos dois momentos na modernidade da dança ocidental que estabeleceram contatos entre movimento do corpo e a voz. O primeiro momento, com o próprio Laban em 1910, ocorre no contexto de sua escola Tanz Ton Wort, quando ele recorreu ao uso do grito e aos sons guturais (LOUPPE, 2012). Porém, em uma atitude de insubordinação à presença até então permanente da música na dança, mais do que a uma adesão propriamente à voz. O mesmo tipo de empreendimento, ao que afirma a autora, foi realizado por Mary Wygman [1886-1973, Alemanha] quando esta bailarina recitou Assim falou Zaratustra de Nietzsche enquanto dançava na galeria Dadá, em 1916.

Insubordinações estas que, segundo a mesma autora, também apareceram nas expoentes da dança moderna Doris Humphrey [1895-1958, EUA] e Martha Graham [1894-1991, EUA], defensoras da respiração audível, dos tons abafados e da leitura de textos em cena. Mas, sobretudo, defensoras do silêncio. E o segundo momento representado por uma geração posterior de coreógrafos contemporâneos que, de acordo com Louppe, empregaram o verbal na dança como forma de depositar palavras "nos lábios de seres feridos" tal como Pina Bausch [1940-2009, Alemanha] e Win Vandekeybus [1963, Bélgica], com textos de procedências diversas e, inclusive, de seus próprios bailarinos (2012, p.318-321). Das palavras da autora, notamos que, enquanto a presença da voz nas danças de Laban, Wygman, Humphrey e Graham se dava principalmente como uma conduta de negação da presença da música, na contemporaneidade ela é adotada em uma posição central que antes não lhe havia sido dada.

Ainda de acordo com a teórica, quando usada como recurso cênico de dança, a voz cumpre pelo menos dois papéis distintos, a depender do que nela se deseja destacar. Um papel possível seria aquele que valoriza o aspecto sonoro rítmico 
da voz, não como fundo, mas como força geradora do próprio movimento. E um segundo papel seria aquele que valoriza o aspecto textual e literário do que é dito em cena com "a ressonância conotativa das palavras associada à ressonância dos movimentos" (2012, p.319). Embora o balé tenha se mantido resistente a esses usos insurgentes, Veronique Doisneou, por sua vez, se dispõe corajosamente desses dois tipos de usos da voz e se firma como obra. Na opinião de Laurence Louppe:

\begin{abstract}
A presença sonora da linguagem no palco coreográfico parece infringir dois elementos canónicos da tradição da dança: a dança é silenciosa e a dimensão sonora autorizada (e obrigatória) deve ser de ordem musical. (2012, p.318)
\end{abstract}

Pelos exemplos trazidos acima, é intrigante perceber que, embora os tenha havido, a formação artística massiva em dança, mesmo a partir da modernidade - e aqui nos referimos ao balé especialmente, a dança moderna e algumas abordagens da dança contemporânea que seguem tal linha de pensamento -, continua a essencializar-se enquanto arte precisamente do movimento. Como consequência desse raciocínio exclusivista é que o foco de pesquisas, narrativas e técnicas de grande parte da dança ocidental deram-se prioritariamente em torno do aprimoramento biomecânico e especializado do corpo movente.

Como resultado dessa concepção de dança, alguns olhares relutantes foram desencadeados. Como os discursos comuns, ainda replicados nos ambientes de formação em dança, de que é impossível definir em palavras o que o corpo sente enquanto dança; ou que a dança trata do inexprimível ou, ainda, que o bailarino fala através do movimento. Embora não vejamos tais olhares como problema, já que a dança pode ser isto, como pode também ser tantas outras coisas; o que pretendemos desenvolver aqui é uma discussão sobre a potência da voz/palavra como corpo e arena para reflexões contemporâneas em dança, tal como ocorre em Veronique Doisneau. Peça coreográfica na qual palavra, voz, presença e dança são tornadas obra, ou performance, para tratar de forma desnudada a carreira de uma bailarina de balé.

Em um artigo que discute a relação entre corpo e poesia, a pesquisadora Adriana Carolina Hipólito de Assis afirma ser possível estimular a relação, muitas vezes evitada, entre o não-verbal e o verbal tomando a palavra como parte do corpo expressivo. Sobre isto, a autora adverte:

Dicotomias ainda perceptíveis em críticas que persistem em estabelecer fronteiras acirradas entre códigos verbais e não verbais; contador e ouvinte, como se fossem corpos que não se afetam. Ainda mais em poéticas contemporâneas que estabe- 
lecem, por exemplo, elos audíveis-visuais-táteis em um só corpo. (ASSIS, 2010, p.399)

Tal como se percebe nesta passagem de Assis, as separações estanques entre não-verbal e verbal e dicotomias intransigentes são cada vez mais postas em questão na contemporaneidade. Neste sentido, a fim de investigar como a relação corpo-voz-dança pode/poderia constituir bases culturais e práticas artístico-discursivas importantes e transformadoras da dança, recorremos a Paul Zumthor [1915-1995, Suíça] (1993, 2000) medievalista, crítico literário, historiador da literatura e linguista.

Importa saber que, para este autor, a voz é uma constituinte da cultura e responsável - como outras práticas simbólicas e sociais - pela preservação das tradições e das práticas discursivas (2000). Em detrimento disso, os textos e suas leituras possuem performatividades assumidas pela oralidade. A voz, nas palavras de Zumthor, é um lugar simbólico por excelência. Isso ocorre porque a voz estabelece relação de alteridade quando desaloja o ser humano do seu corpo e o põe em contato com a exterioridade, ao mesmo tempo em que o joga para dentro de si mesmo em estado de escuta. Sobre essa potência da voz, Paul Zumthor diz que "A transmissão de boca a ouvido opera o texto, mas é o todo da performance que constitui o lócus emocional em que o texto vocalizado se torna arte" (1993, p.222; grifos do autor).

Assinalada a importância da voz para a construção de performatividades na cultura, salientaremos, a seguir, como ela pode constituir outras experiências no campo artístico da dança. Para enveredar neste campo conceitual e suas relações com a arte e a estética, recorremos a Susanne Langer [1895-1985, EUA]. Tal autora, em seu livro Sentimento e Forma ([1953], 1980), entende a arte como a criação de formas simbólicas do sentimento humano. O símbolo refere-se ao sentimento e às formas, aos dispositivos capazes de tornar o que existe em outra coisa. Na acepção desta autora, a arte é constituída de símbolos que articulam e apresentam conceitos, sensações e expressões.

Do entendimento da autora, depreendemos que as nossas experiências - e nesse caso a experiência em/de dança - são formadas por símbolos. Ou seja, por percepções e expressões capazes de sinalizar sobre nossos estados e sentimentos. Para Langer, a simbolização na arte é percebida pelo que ela é, porque "o símbolo é usado para articular ideias de algo sobre o qual desejamos pensar" (1980, p. 29). A autora defende que os símbolos artísticos são intraduzíveis e existem na inteireza da forma que assumiram ser. Isso porque cada um dos objetos levado à cena carrega consigo sentidos. É o que ocorre em Veronique Doisneau, por exemplo. Peça coreográfica na qual os seus símbolos constituintes: saia, sapatilha, roupa de 
ensaio, garrafa d’água, tutu, palco despido de ornamentos, movimentos e a permissão da bailarina para pronunciar-se por meio de sua voz "dão o recado" que têm que dar, constituem-se em obra.

Ao nos remetermos neste texto sobre a importância da voz como fio condutor desta obra de dança e como isto representa uma tensão para a organização do balé, percebemos também uma relação conflituosa da dança em meio às demais expressões artísticas. Langer traz esta questão no mesmo livro, em seu texto Poderes Virtuais. Texto no qual a autora afirma a permanente relegação da dança em relação às outras manifestações artísticas. Ela aponta que a dança já foi vista como uma arte musical, uma vez já ter sido figurada como emoção estimulada pelos sons. Que já foi ligada às artes plásticas, quando pensada como imagens em ação; concepção esta principalmente relacionada ao balé por ele ter sido entendido, muitas vezes, como pinturas em movimento. Assim como também já foi vista como pantomima, por ser uma arte dramática. No entanto, ao que defende Langer, "a pantomima, como os padrões de movimento puro, imagens plásticas e formas musicais, é material de dança, algo que pode tornar-se um elemento balético, mas a dança em si é outra coisa" (1980, p.181).

No contexto desta autora, a dança é gesto ou um elemento na exibição do gesto. O sentido imaginado como expressão gestual imprime experiências objetivas e subjetivas do atuante reveladas em cena. Observamos isso no decorrer da apresentação Veronique Doisneau. Solo no qual o balé é descortinado sob a ótica de uma bailarina que não é uma grande estrela, que está prestes a se aposentar e que constitui histórias e experiências corporalizadas que, aos olhos da hierarquia desta dança, quase sempre são ofuscadas enquanto materiais artísticos.

O coreógrafo Jérôme Bel orienta esta dança sob um nítido engajamento poético que explora as memórias tatuadas no corpo da bailarina e a permissividade de falar desnudamente sobre o balé. As pausas, os silêncios, o discurso, a voz e as imagens que organizam esse trabalho constituem sentidos indiscutíveis para o balé. Veronique, por sua vez, revela como a imagem bonita e mágica do balé de repertório (como o Corpo de Baile imóvel ou movendo-se lentamente enquanto a primeira bailarina realiza seus solos) pode ser extremamente tediosa, cansativa ou repressora para a bailarina que ocupa o posto de sujet.

Por exemplo, em certa altura da obra,Veronique relata sua função no segundo ato do balé O Lago dos Cisnes [1877, Rússia] em que ela - uma das trinta e duas bailarinas que compõe o cenário humano para a apresentação do solo da bailarina principal - faz algumas poses e movimentos de transição. Nas 
palavras dela: "a coisa mais horrível que fazemos" por causa das dores e câimbras ocasionadas pelas posições e o estado de impassibilidade ao longo de oito minutos. Para que a plateia entenda do que se trata, e veja este trecho pela ótica do Corpo de Baile e não pela perspectiva da bailarina solista, Veronique realiza, em rigorosos oito minutos, as exatas poses coreografadas e a forma como ela e as bailarinas do Corpo de Baile experienciam este momento. Formas fatigantes, corpos ausentes mesmo em cena.

Do que foi dito acima, percebemos que a dimensão discursiva da obra Veronique destaca-se instaurando uma espécie de performance coreo-vocal. O lugar de bailarina sujet, que a ela é destinado ocupar, é reiterado em toda obra com a finalidade de compartilhar o quão incômoda pode ser essa posição. Importante destacar que, neste trabalho, entendemos discurso assim como o linguista José Luiz Fiorin [1942, Brasil]. Para este autor, discurso é a combinação de elementos linguísticos e/ou não-linguísticos usados por nós com o intuito de exprimir pensamentos, falar do mundo exterior ou interior (1998, p.11). De acordo com ele, falamos a partir da nossa posição social. Fiorin afirma que, quando comunicamos algo através de nossos discursos, inevitavelmente, agimos sobre o mundo. Significa dizer que ao exercer esse papel de agentes, produzimos sentidos com a finalidade de influir sobre o outro, de conquistar sua crença, de mudar seu comportamento ou opinião. Segundo ele, mesmo quando o propósito de nossos discursos não é o fazerfazer, ao comunicarmos algo a outrem, exercemos também o fazer-saber. Ou seja, tornamos o nosso interlocutor detentor de um conhecimento (1998, p.74). Inquietante perceber que se a fala, para o autor, é uma exteriorização psico-físico-fisiológica individual, enquanto o discurso é uma expressão do indivíduo orientada socialmente e que se manifesta através de meios linguísticos e/ou não-linguísticos, o que provavelmente nos é incômodo - ou encantador - nos discursos verbais e gestuais de Veronique é o que não se quer saber/ver do que ela diz/faz. É o que foi feito para não ser voz. Como, impreterivelmente, "Uma pessoa expõe-se nas palavras proferidas", assim com advoga Zumthor (1993, p.222), é exatamente nessa exposição impudica das ações de Veronique que reside uma parcela do que nos toca em seu solo.

Na opinião do professsor de história da dança Ramsay Burt [1950, Inglaterra] em seu artigo Revisiting 'No tospectacle': self unfinished and Véronique Doisneau (2012), Veronique Doisneau joga para o público a responsabilidade das ações invisíveis aos olhos de quem assiste um balé clássico e se deleita com as belas imagens criadas durante a dança. Esse solo, por sua vez, evoca um estado subjacente de crueza em oposição ao ambiente apa- 
rentemente esplendoroso e irreal criado pelos balés românticos. De acordo com o historiador:

\begin{abstract}
De certa forma, Doisneau descreveu seu trabalho como qualquer outro tipo de trabalho. Vestindo roupas de ensaio, com um pequeno microfone de boca, uma garrafa de água mineral, ela disse à plateia quantos anos tinha, falou sobre seus filhos, seu salário e há quanto tempo está na companhia. Também mencionou a lesão grave que possivelmentea impediude progredir para além de 'sujet'. É quase tão constrangedor ouvir alguém admitir o quão pouco ganha quanto vê-lo despir-se desta maneira em público. Igualmente constrangedor é perceber como os riscos físicos e perigos da dança são cotidianamente assuntos tabus. Doisneau não estava partilhando confidências íntimas com o seu público, apenas indicando uma informação fatídica. A peça, portanto, estabeleceu o status de vulnerabilidade socioeconômica e física a fim de fundamentar sua atuação em uma ampla rede de relações entre o balé e o social e, assim, esvaziar as fantasias transcendentais que as performances de La Bayadère, Giselle e O Lago dos Cisnes normalmente tentam evocar.(BURT, 2012, p.o6; tradução nossa)
\end{abstract}

Em suma, Veronique Doisneau nos mostra que a vida de bailarina é como a de qualquer outro profissional que vive rotinas exaustivas, competições, cumpre horas e por fim, aposentase. Esta obra desnuda o fato de que o glamour e a delicadeza representados em cena, nos balés de repertório, fazem parte de papéis previamente estabelecidos e lugares instituídos pela tradição artística. A bailarina etérea, que por praticamente dois séculos apareceu desumanizada e romântica, revela nessa obra sua vulnerabilidade para virar ao avesso o que parecia sublime demais.

E se voz é corpo, por que não fazê-la dança?

O autor Paul Zumthor (2000) entende o corpo como um emaranhado de percepções e sensibilidades que reverberam no contexto da voz/corpo social performático. Seus estudos, que partem de suas pesquisas sobre as poesias medievais, são frutos de diálogos intertextuais e interdiscursivos que compõem o complexo tema da performance da oralidade. A noção de performance se dá pela presentificação do corpo e do texto como força energética da linguagem. Para isso, ele propõe uma poética da oralidade dada no ambiente e no corpo em ação. Um corpo-mundo que exterioriza emoções e expressões. Para ele:

O corpo é o peso sentido na experiência que faço dos textos. Meu corpo é a materialização daquilo que me é próprio, realidade vivida e que determina minha relação com o mundo. Dotado 
de uma significação incomparável, ele existe à imagem do meu ser: é ele que eu vivo, possuo e sou, para o melhor e para o pior. (ZUMTHOR, 2000, p.23)

Se a escrita é uma performance impregnada de poderes e afetos de quem escreve e lê o mundo, quais seriam os papeis da voz e da leitura para a prática artística/política da dança? Como a dança, permeada pela realidade corporal e oral, pode usar a voz como ferramenta para estar no mundo?

Acreditamos que a dança, como manifestação artística e problematizadora de seus fazeres, tem desenvolvido nas últimas décadas espaços interessantes para a manifestação oral e escrita de seus artistas. A título de exemplo, citaremos RamDam (1995) da Companhia de Dança Maguy Marin [França], Faladores (2008) da Companhia Mário Nascimento e Proibido Elefantes (2012) da Gira Dança [Brasil]. Propostas lançadas para tecer distintas sensorialidades para dança, nas quais gesto e voz (co)elaboram performances sonoro-cinéticas. Ou seja, novas relações entre elas.

Neste ínterim, retomamos o exemplo de Veronique Doisneau para refletir sobre a forma como as práticas discursivas agem nos sujeitos do balé e provocam sensações para além da beleza de sua forma. Como ratifica Zumthor:

[...] no processo de atualização do texto, a obra criada, a partir da interação entre o conhecimento presente no texto e o dizer performático, é única, pois a performance modifica o conhecimento, ela não é simplesmente um meio de comunicação, é um meio de criação. (2000, p.37)

Palavras estas que nos possibilitam dizer que a performance dirigida por Jérôme Bel presentifica camadas simbólicas constitutivas dos processos históricos e estéticos do balé manifestados como corpo discursivo em cena. O solo não se trata apenas da narração de vida da bailarina que dá nome à obra, trata-se de uma leitura mais ampla, de um discurso coletivo, do contexto de uma dança apoderada pelos espaços teatrais e pelos lugares de legitimação artística e profissional do bailarino. Sobre esses percursos de mudez e de biografias anuladas da dança o pesquisador em dança Jaime Conde-Salazar [1974, Espanha], no artigo En el punto de fuga, ressalta:

[...] mas as coisas não são tão fáceis. Primeiro, porque na dança teatral convencional os bailarinos não falam, não lhes supõe voz própria e, portanto, não têm sua própria história para contar. Como evidencia Cedric Andrieux, eles estão lá para diferentes técnicas de dança que foram inventadas ao longo dos últimos dois séculos. Ou, se quisermos avançar ainda mais, sua única missão é 
oferecer o seu corpo para distintas representações do outro: eles, uma vez que estão no palco, perdem o que chamamos de biografia. (CONDE-SALAZAR, 2012, [n.p.]; tradução nossa)

Enxergamos a palavra na dança como uma performance de enfrentamento, um ato cheio de intensidade para trazer outros tons para a recepção e também para as discussões sobre o balé. Se, assim como afirma Lepecki (2012, [n.p]), o "fazer coreográfico não significa estar condenado ao movimento", a oralidade na dança pode nos revelar muito sobre as memórias, sensações e políticas do corpo como expressão artística.

Ao desmistificar a forma clássica, Veronique Doisneau e Jérôme Bel revelam ao público o custo dos prazeres gerados pelo espetáculo dos balés de repertório, exibem a hierarquia das companhias de dança e mostram a condição enrijecida em que se encontra o balé enquanto formação, profissão e expressão artística. O fôlego que Veronique sempre retoma para continuar sua fala com a plateia é a demonstração física de seu cansaço e, ao mesmo tempo, do esforço para manter o balé em pé.

Ao fim, percebemos que o percurso ainda é muito longo para tais debates. Acreditamos que a dança, e principalmente o balé, necessite de discussões menos ingênuas e enrijecidas sobre sua feitura. A mudez, o corpo ausente (e por isso mecânico) que se tornou o balé são sintomas de uma carência de reflexões que teimam em ser adiadas ou discriminadas como não dança. Por isto, continuaremos a provocar suas esferas e a buscar conexões que possam ampliar seus sentidos e entendimentos rumo a um corpo discursivo de si e do mundo atual em que vivemos. Por que não? 
ASSIS, Adriana Carolina Hipólito de. Alguma crítica: a dança do corpo poético em "Um rio chamado tempo, uma casa chamada terra". Crítica Cultural: Santa Catarina, 2011. Disponivel em: http://www.portaldeperiodicos.unisul.br/index.php/Critica_ Cultural/article/viewFile/J72/pdf_25. Acesso em: 26 mar. 2015. BEL, Jérôme.Veronique Doisneau 1. 9"26'. Disponivel em: https://www.youtube.com/watch?v=OIuWY5PInFs. Acesso em: 26 de mar. de 2015.

BURT, Ramsay. Revisiting 'No To Spectacle': Self Unfinished and Véronique Doisneau. Montfort University, Inglaterra, 2012. Disponivel em: https://www.dora.dmu.ac.uk/bitstream/ handle/2086/145/Revisiting\%20no\%20to\%20spectacle.pdf?sequence=1. Acesso em: 26 mar. 2015.

CONDE-SALAZAR, Jaime. Em El punto de fuga, 2012. Disponível em: http://www.continuumlivearts.com/wp/?p=2888. Acesso em: 26 mar. 2015.

FIORIN, José Luiz. Linguagem e ideologia. 6a ed. São Paulo: Editora Ática, 1998.

LABAN, Rudolf Von. Dança Educativa Moderna. São Paulo: Ícone, 1990.

LANGER, Susanne. Sentimento e Forma (Trad. Ana Maria G. Coelho e J.Guinsburg). São Paulo: Perspectiva, 1980.

LOUPPE, Laurence. Poética da dança contemporânea. Lisboa: Orfeu Negro, 2012.

NADA EXPANDIDO. Conversa com André Lepecki. 20"14, 2012. Disponivel em: http://www.nadaexpandido.com.br/?p=184. Acesso em: 25 mar. 2015

ZUMTHOR, Paul. A performance. In: A letra e a voz. São Paulo: Cia. das Letras, 1993.

ZUMTHOR, Paul. Performance, recepção, leitura. Tradução de Jerusa Pires Ferreira e Suely Fenerich. São Paulo: EDUC, 2000. 